\title{
INTERDEPENDENCY BETWEEN ECONOMIC PERFORMANCE AND HIV PREVALENCE IN COUNTRIES OF SUB-SAHARAN AFRICA
}

\author{
L'ubica Zubal'ová1 ${ }^{1, a,}$, Kristína Drieniková ${ }^{2, b}$ and L’udmila Smákováa ${ }^{3}$, \\ 1,2,3 University of Economics, Faculty of Commerce, Department of International Trade, \\ Dolnozemská cesta 1, 85235 Bratislava, Slovak Republic \\ alubica.zubalova@euba.sk, bkristina.drienikova@euba.sk, cludka.smakova@gmail.com \\ *Corresponding author
}

Cite as: Zubalová, L., Drieniková, K., Smáková, L'. (2020). Interdependency between the economic performance of a country and HIV prevalence in Sub-Saharan Africa, Ekonomicko-manazerske spektrum, 14(2), 52-62.

Available at: dx.doi.org/10.26552/ems.2020.2.52-62.

Received: 18 October 2020; Received in revised form: 28 October 2020; Accepted: 5 November 2020; Available online: 25 November 2020

Abstract: The HIV/AIDS threat, as a development obstacle in the underdeveloped world, has persisted for years. Globally, 37.9 million people are HIV positive and the majority, or 70\% of them, live in Sub-Saharan Africa, a region with insufficient resources to fight the infection. HIV infection, if it progresses to AIDS, reduces labor force, decreases productivity, increases costs of health services and thus has a negative impact on a country's economic performance. The research presented in the paper analyzed HIV prevalence and GDP per capita of all SubSaharan countries, disproving the initial hypothesis that the highest HIV prevalence is found among the poorest counties. Paradoxically, HIV incidence is higher in countries with higher middle income like Botswana and the Republic of South Africa. Of the ten most affected countries, only four are ranked in the least developed category. Inverse dependency between the rate of Human Development Index and HIV prevalence, examined using the regression model in the gretl statistical software, was not confirmed and thus high HIV prevalence in population does not automatically lead to extreme poverty. HIV and AIDS form one of several factors affecting economic development of the region of Sub-Saharan Africa. The main aim of the paper is to assess the influence of HIV/AIDS on the economic development of Sub-Saharan nations, using the OLS regression model in gretl, interdependency between the economic performance of a country (GDP per capita) and HIV prevalence in its active population (aged 15-45) to find out whether HIV is among the major factors negatively affecting development in the region of Sub-Saharan Africa.

Key words: HIV/AIDS, prevalence, development, Sub-Saharan Africa

JEL classification: I15

\section{Introduction}

Out of approximately 7.8 billion people living in the world, every 200th person is infected with HIV. According to UNAIDS data, in 2018 there were by estimation 37,900,000 HIV positive people including children. The worst situation is in Sub-Saharan Africa, which is home to $70 \%$ of the world's HIV positive people. Estimated $2 \%$ of the population of SubSaharan Africa are carriers of the virus causing AIDS (UNAIDS, 2020). An incurable, but 
treatable disease such as HIV in the extent seen in Sub-Saharan Africa is a source of physical and mental suffering of individuals, families, and whole communities. Economic theories agree that HIV reduces labor force, decreases productivity, and thus has a negative impact on a country's economic performance: production, services, foreign trade, purchasing power, etc. A high percentage of the infected population burden the social and health care systems and majority of the developing countries are unable to provide the latest HIV antivirals, nourishment, and prevention of further spreading of the disease. It is in the poorest countries in particular that unfavorable conditions enable HIV to turn into AIDS. Unfortunately, some African countries denied the existence of HIV in their territory when the disease originally broke out, allowing the infection to spread, especially in Southern Africa, which led to a drastic decline in the average life expectancy in the region in the 1990s.

The paper is focused on examination of the interdependency between the economic performance of a country (GDP per capita) and HIV prevalence in its working population aged 15-49, with the use of the OLS regression model in the gretl statistical software, working with the assumption that higher percentage of infected will occur in the countries with lower GDP per capita. The aim of the paper is to assess the influence of HIV on the economy of a country by means of the scientific method.

The studies on HIV/AIDS prevalence and economic performance have been prolific and versatile. Lovasz and Schipp (2009) investigated the hypothesis that HIV / AIDS has negative impact on economic growth and proved its validity. Bonnel (2000) discussed the relationship between HIV/AIDS and economic growth by analyzing the impact of the disease on national economies from a global perspective. He explained that the epidemic threatens countries' economic development and prosperity, because the infection damages their physical, human, and social capital. In countries with high HIV/AIDS prevalence, provision of basic social and other needs is at stake, as local and national institutions focus primarily on halting or at least slowing the spread of the disease. His analysis is based on the hypothesis that presence of the disease in an economy reduces the per capita income growth rate. The impact on GDP growth is even more substantial for the countries with high prevalence rates, especially in the case of a typical Sub-Saharan African country. Dixon et al. (2001) analyzed the relationship between HIV prevalence and GDP in forty-one African economies between 1960 and 1998. Their results indicated that countries with relatively low HIV prevalence rate show "normal" GDP growth (normal economic expectations) during the period under review, while on the other hand, in countries with relatively high HIV prevalence the macroeconomic impact of the HIV epidemic is unclear (deviates significantly from normal). Lou et al. (2014) examined the 2011 data on HIV/AIDS and confirmed that HIV/AIDS mortality, prevalence, and incidence rates were inversely correlated with the Human Development Index HDI. Essing et al. (2015) examined the relationship between GDP per capita and HIV prevalence in African countries. In their study, they conclude that both variables - the number of people living with HIV and HIV related deaths - negatively affect the economy of the country. Whiteside (2010) considered "HIV/AIDS the major threat to development, economic growth and poverty alleviation in much of Africa“".

Maijama'a and Mohammed (2013) examined the impact of the disease on economic growth and development in Nigeria as well as the epidemic's effect on savings and the standard of living. Their findings indicate that the spreading and rising prevalence of HIV/AIDS in Nigeria negatively affects its real GDP growth, hampers its macroeconomic stability, and has exacerbated income inequality and increased poverty. Haruna (2017) examined the social and economic effects of HIV/AIDS in Nigeria as well. Among the social effects, the discrimination and stigmatization of the infected are the most visible negative effects and primary social consequences of the disease. Discrimination related to the disease has remained an enormous barrier to people seeking treatment or admitting their HIV/AIDS 
status publicly. The HIV/AIDS stigma involves prejudice and discrimination and is believed to cause social isolation, emotional stress, and loss of economic support of the infected, or even increase in violence against women in Nigeria. The economic effects have been associated with rising morbidity and mortality rates for certain age groups. Most of the infected fall within the age category of 15-49 years and the epidemic cuts short the productive lives of this group, reduces their savings and increases health care expenditures. (Essig et al., 2015)

Meanwhile, there are multiple dimensions of views on the impacts of HIV prevalence. Bhargava and Docquier (2008) dealt with the relationship between HIV prevalence rate, economic development, and medical brain drain in Sub-Saharan Africa. The authors conclude that the rate of medical brain drain is associated with an increase in the number of adult deaths in countries where HIV prevalence exceeds 3 percent; a doubling of the medical brain drain rate is associated with a 20 percent increase in adult deaths from AIDS. Leon et al. (2017) discussed the role of education in the fight against HIV/AIDS in Sub-Saharan Africa. They conclude that the effect of education on the HIV pandemic in the region shifted from acting as a risk factor in the earlier stages to becoming more of a social vaccine against HIV. The variation in quality of the public health environment in particular could be a driving factor of this historical change in the relationship between education and the disease. Dauda (2017) studied HIV/AIDS in relation to human capital measures in West Africa and confirmed its negative impact on life expectancy and no significant impact on school enrolment. Increase in GDP income had no impact on human capital development, as African countries do not increase spending on human development including health care. Johnston et al. (2015) also discussed stigmatization and the social roots of the disease. Abdulsalam (2010) developed a model of Nigerian economy and conducted research on the impact of HIV on macroeconomic data in Nigeria and confirmed the link between HIV/AIDS prevalence and decreased output in the agriculture and manufacturing sectors and increased governmental spending on prevention and treatment. Upadhyay and Gezahegn (2014) investigated the effect of health on economic development and confirmed the adverse effect of HIV/AIDS on accumulation of human capital and therefore also on the growth of the entire economy in terms of accrual income of households and companies. Odugbesan and Rjoub (2020) evaluated the impact of HIV prevalence on sustainable development in SubSaharan Africa and their study examined long-term causal link between HIV and sustainable development. Sustainable development is not compromised by HIV/AIDS and HIV does not significantly respond to sustainable development. Results of the study by Nketiah-Amponsah et al. (2019) show that a $1 \%$ increase in HIV prevalence leads to a $0.47 \%$ decrease in income per capita. Assiedu et al. (2015) pointed out negative effects of HIV prevalence on foreign direct investments which decreases the perspective of positive economic development.

\section{Methodology}

A thorough analysis of various scientific and specialized sources allowed us to gain insight into the HIV/AIDS issue in the context of the impact of the disease on the economic development of the nations of Sub-Saharan Africa and allowed us to identify the key factors contributing to the high HIV prevalence in the relatively rich states of the region. Since the paper's main aim is to assess the influence of HIV/AIDS on the economic development of Sub-Saharan countries, we decided to conduct an analysis based on the following hypothesis:

The poorest states of Sub-Saharan Africa, i.e., those with very low level of economic development, will be the most significantly affected by the HIV/AIDS epidemic.

Our hypothesis was first and foremost built on the cycle of poverty theory, which in its essence presupposes a negative correlation between epidemics and economic development. 
Therefore, we assumed that our analysis would confirm this hypothesis. We compared HIV prevalence and GDP per capita of individual countries of Sub-Saharan Africa by ranking the forty-eight Sub-Saharan nations based on their GDP per capita in USD, from the lowest to the highest, using the data available from the World Bank (2019). Subsequently, we created another ranking, comparing HIV prevalence in the Sub-Saharan countries, from the highest to the lowest. An empirical study and comparison of the two ratings led us to a surprising conclusion which refuted our original hypothesis, as paradoxically the highest HIV prevalence is found in countries that are far from the poorest and have higher GDP per capita, like Swaziland, Botswana, or the RSA.

Since we considered an assessment of economic development based purely on GDP per capita to be misleading, we decided to additionally verify our hypothesis by means of econometrics by creating a regression model in gretl. The most common economic model is a linear model consisting of two variables and an additional random component, which is noted as follows:

$$
y_{i}=\beta_{0}+\beta_{1} x_{i}+u_{1}
$$

where $\mathbf{y}$ is a dependent variable, the value of which depends on the value of the independent variable $\mathrm{X}$;

i

$\mathbf{X}$

$\boldsymbol{\beta}_{0}$ and $\boldsymbol{\beta}_{1}$ is the ith study of variable $\mathrm{Y}$ (endogenous variable), the development of which we mode;

represents the ith study of variable $X$ (exogenous variable), which is the assumed main factor influencing the development of $\mathrm{Y}$;

are used to ascertain whether we can consider the independent variable $\mathrm{X}$ to be a relevant source of changes in value of the dependent variable Y (Lukacik et al., 2011).

We assessed the influence of HIV/AIDS on the economic development of countries using a more complex indicator of poverty than GDP per capita - the Human Development Index (HDI). The HDI represents the dependent variable, the development of which we assume to depend on the independent variable, i.e., HIV prevalence expressed as percentage. To secure the strongest objectivity of the model, we decided to supplement HIV prevalence with two additional independent variables, namely Corruption Perceptions Index (CPI) and Index of Economic Freedom (IEF), which may influence the Human Development Index as well. The use of cross-sectional data means that we can disregard the additional random component, because its value is equal to zero. The parameters $\beta_{0}$ and $\beta_{1}$ are used to ascertain whether we can consider the independent variable $X$ to be a relevant source of changes in value of the dependent variable Y. For the assessment of the given parameters, we need to use estimators which in terms of econometrics should meet two key, closely linked requirements: they should be unbiased and effective.

An estimator can be described as effective if its dispersion is lower or equals the dispersion of any other unbiased estimator compared in the modelling process. The most frequently used estimator is the least squares estimator. It is considered the best linear unbiased estimator provided that all the Gauss-Markov conditions are met.

Since the OLS (Ordinary Least Squares) regression model was used for our econometric model, we employed the principles of operation of this estimator. Once we uploaded the input data and received the resulting display in gretl, we had to verify the model. The verification itself consisted primarily of testing the significance of regression model parameters via a Ttest, testing the significance of the model, taken as a whole, via an F-test, and verifying the presence of heteroscedasticity via the White test. For completeness' sake, we add that heteroscedasticity of a random component means non-fulfillment of the penultimate Gauss- 
Markov condition, which states that "the dispersion of random components for different values of explanatory variable is not identical" (Lukacik et al., 2011). If this condition were not met, the least squares estimator would be ineffective.

We faced a great number of problems concerning obsolescence, inaccessibility, and incompleteness of relevant data related to the issue. Originally, we wanted to include also government expenditure on health care from WHO's database, but we discovered that their statistical data for countries of Sub-Saharan Africa are so insufficient that using them to come to a relevant and objective conclusion is not possible.

\section{Results}

The UNAIDS data show, that there are between 31,100,000 and 43,900,000 HIV positive people living in the world, 70\% of whom can be found in Sub-Saharan Africa (UNAIDS, 2020). Table 1 provides a closer look at the global situation. The highest rate of infection is in the region of Sub-Saharan Africa ${ }^{1}$, where the amount of infected people reaches 25,700,000, two thirds of the world's HIV positive people. On average, $2 \%$ of the Sub-Saharan Africa population is infected with HIV. The most affected Sub-Saharan region is Eastern and Southern Africa, where 53\% of all HIV positive people come from. The figures are still high, even though the amount of infected people has decreased by 30\% since 2010 (KFF, 2019). Data concerning numerous countries of the Middle East and Northern Africa (Libya, UAE, Saudi Arabia, Turkey, Oman, and Yemen) are not available, but the estimate for the region is 240,000 people, or $0.1 \%$ of all HIV positives, with year-over-year increase (Avert, 20210). Oraby (2019) assumes that $2 \%$ of the infected live in MENA, with mortality almost doubled over the last decade due to stigma and discrimination.

Even though new HIV infections have been reduced by 39\% between 2000 and 2019, in 2019 an estimated 1.7 mil. acquired an HIV infection (HIV.gov, 2020).

Table 1: HIV infected per region (2017, children included, in thousands, the lowest and highest estimates), prevalence in the active population (2017, aged 15 to 49 )

\begin{tabular}{|c|c|c|c|c|c|}
\hline Region & $\begin{array}{l}\text { The Amount of } \\
\text { Infected People }\end{array}$ & $\begin{array}{l}\text { The Lowest } \\
\text { Estimation }\end{array}$ & $\begin{array}{l}\text { The Highest } \\
\text { Estimation }\end{array}$ & $\begin{array}{l}\text { Percentage of } \\
\text { Infected People }\end{array}$ & $\begin{array}{l}\text { HIV } \\
\text { Prevalence in } \\
\%\end{array}$ \\
\hline $\begin{array}{l}\text { Eastern and southern } \\
\text { Africa }\end{array}$ & 19,600 & 17,500 & 22,000 & $53.2 \%$ & $6.8 \%$ \\
\hline $\begin{array}{l}\text { Western and Central } \\
\text { Africa }\end{array}$ & 6,100 & 4,400 & 8,100 & $16.6 \%$ & $1.9 \%$ \\
\hline Asia Pacific region & 5,200 & 4,100 & 6,700 & $14.1 \%$ & $0.2 \%$ \\
\hline $\begin{array}{llr}\text { Western and } & \text { Central } \\
\text { Europe } & \text { and } & \text { North } \\
\text { America } & & \end{array}$ & 2,200 & 1,900 & 2,400 & $6.0 \%$ & $0.3 \%$ \\
\hline Latin America & 1,800 & 1,500 & 2,300 & $4.9 \%$ & $0.5 \%$ \\
\hline $\begin{array}{l}\text { Eastern Europe and } \\
\text { Central Asia }\end{array}$ & 1,400 & 1,300 & 1,600 & $3.8 \%$ & $0.8 \%$ \\
\hline Caribbean & 310 & 260 & 420 & $0.8 \%$ & $1.7 \%$ \\
\hline
\end{tabular}

\footnotetext{
${ }^{1}$ To arrive at the amount of HIV positive people in Sub-Saharan Africa we added up the numbers derived from UNAIDS for Eastern and Southern Africa and for Western and Central Africa.
} 


\begin{tabular}{|c|c|c|c|c|c|}
\hline $\begin{array}{l}\text { Middle East and } \\
\text { Northern Africa }\end{array}$ & 220 & 150 & 300 & $0.6 \%$ & $0.1 \%$ \\
\hline TOTAL & 36,830 & 31,110 & 43,820 & $100 \%$ & 0.9 \\
\hline
\end{tabular}

Source: UNAIDS (2020)

The percentages regarding prevalence in individual regions are as follows: the prevalence of $1.4 \%-2.6 \%$ is found predominantly in Western and Central Africa. However, in the regions of Eastern and Southern Africa, HIV prevalence amounts to 6.8\%, which means that approximately 7 people out of 100 are infected with HIV. Thus, the average HIV prevalence in the region of Sub-Saharan Africa amounts to 4.4\%. The prevalence in all other regions, except for the Caribbean, is lower or equals the world-wide average of $0.8 \%$. Nevertheless, it is necessary to take into consideration statistical discrepancies and the fact that not all countries publish information regarding HIV (UNAIDS, 2020).

The comparison of GDP per capita of forty-eight states of Sub-Saharan Africa with their HIV prevalence in working population aged 15- 49 led us to the conclusion that the highest HIV prevalence is found in:

- Swaziland - with 27.4\% HIV prevalence in 2017; thus, according to official statistical data, approximately one third of the population is HIV positive (UNAISD, 2020). The survey conducted between 2010-2011 by Justman, J. et al. (2011) confirmed even then that Swaziland was globally the most endangered country.

- Lesotho (23.8\%), Botswana (22.8\%), and the RSA (18.8\%), where one fifth of the population is HIV/AIDS positive;

- Zimbabwe (13.3\%), Mozambique (12.5\%), Namibia (12.1\%), and Zambia (11.5\%) where prevalence exceeds $10 \%$ (UNAISD, 2020).

When we compared HIV prevalence of these countries with their GDP per capita, we found out that, paradoxically, these countries were not the poorest in the Sub-Saharan region. Out of the top ten countries with the highest HIV prevalence, only four belong to the least developed group and only Mozambique and Malawi have GDP of less than 500 USD per capita and are the fifth and the third poorest countries, respectively. Only two of the abovementioned countries are among the least developed countries, namely Lesotho and Zambia. When the countries with low GDP per capita are examined, a high HIV prevalence is found only in Mozambique, Malawi, Uganda, Tanzania, Guinea-Bissau, Rwanda, and Togo. As far as Eritrea and South Sudan are concerned, the data regarding GDP per capita were not available, and as regards Mauritius, Seychelles, Sao Tome and Principe, the World Bank does not state their HIV prevalence. Therefore, the comparison of these data rebutted our assumption that the countries most affected by HIV will be those with the lowest GDP per capita, since we assumed that the infection weakens the country and represents one of the reasons for their poverty.

The OLS regression model in gretl was used to verify the results. The Human Development Index for the year 2017 (UNDP, 2017) was set as the dependent variable. As independent variable, HIV prevalence for the year 2015 (as a percentage) was used - the two-year time lag was introduced on the assumption that the presence of HIV does not have an immediate impact on the economy, but its repercussions manifest after some time and translate into measurable results and reports. To achieve greater objectivity, the HIV prevalence was supplemented with two additional control independent variables, namely the Corruption Perceptions Index for the year 2015 and the Index of Economic Freedom for the year 2015, the two of which can influence the overall result of Human Development Index for the year 2017. We expressed the impact of HIV on the economy of individual countries as the following hypothesis: 


$$
\boldsymbol{H D I}_{2017}=\beta_{0}-\beta_{1} x \text { HIV prevalence } 2015+\beta_{2} x \mathrm{CPI}_{2015}+\beta_{3} x \mathrm{IEF}_{2015}+u
$$

The hypothesis presumes that the level of Human Development Index (UNDP, 2017) in the countries of Sub-Saharan Africa for the year 2017 will be dependent upon the level of HIV prevalence in 2015, the Corruption Perception Index for 2015, and the Index of Economic Freedom for 2015. The minus sign next to the HIV prevalence indicates a presumed inverse relationship between the dependent and independent variables, viz. we assume that if the level of HIV prevalence decreases by one unit, the Human Development Index will increase, because the reduced presence of HIV in a country will be reflected in a better Human Development Index ranking. Since we work with cross-sectional data, the random component $u$ at the end of the equation equals zero. The results of the correlation analysis test are shown in Table 2.

Table 2: Regression analysis of HDI and HIV prevalence

\begin{tabular}{lllll}
\hline & Coefficient & Std. Error & t-ratio & p-value \\
\hline Const & 0.230995 & 0.0966007 & 2.391 & 0.0223 \\
HIV_2015 & 0.00723099 & 0.00207467 & 3.485 & 0.0013 \\
CPI_2015 & -0.00135798 & 0.00129031 & -1.052 & 0.2998 \\
IEF_2015 & 0.00532842 & 0.00206007 & 2.587 & 0.0140 \\
\hline
\end{tabular}

Model 1: OLS, using observations 1-48 $(n=39)$

Missing or incomplete observations dropped: 9

Dependent variable: HDI_2017

\begin{tabular}{lclc}
\hline Mean dependent var & 0.510103 & S.D. dependent var & 0.087383 \\
\hline Sum squared resid & 0.178280 & S.E. of regression & 0.071370 \\
R-squared & 0.385577 & Adjusted R-squared & 0.332912 \\
F $(3,35)$ & 7.321334 & P-value(F) & 0.000619 \\
Log-likelihood & 49.72670 & Akaike criterion & -91.45340 \\
Schwarz criterion & -84.79915 & Hannan-Quinn & -89.06591 \\
\hline
\end{tabular}

Excluding the constant, p-value was highest for variable 3 (CPI_2015)

White's test for heteroskedasticity

Null hypothesis: heteroskedasticity not present

Test statistic: $\mathrm{LM}=3,12017$

with p-value $=\mathrm{P}($ Chi-square $(9)>3,12017)=0,959339$

Source: Authors' own elaboration in GRETL program based on the following data: (UNDP, 2017), (World Bank, 2015), (Transparency International, 2016) and (The Heritage Foundation, 2015).

The HIV prevalence in the countries of Sub-Saharan Africa seems highly relevant with the model used - based on the three asterisks in the p-value we can describe this variable as statistically highly significant - or, to put it more precisely, the assessment of the HIV prevalence parameter is statistically significant with a $99 \%$ confidence. The condition of significance was met also by the independent variable (IEF), with $95 \%$ certainty. Since the Corruption Perceptions Index received no asterisks, it seems statistically insignificant in this model.

The hypothesis presuming an inverse relationship between the dependent and independent variable, i.e., the Human Development Index and HIV prevalence, was not confirmed. The results of regression model indicate that if the value of all independent parameters equal zero at the same time, the average change in dependent variable (HDI) equals 0.2310 . The value of 
HIV prevalence is plus 0.00723099 , which can be interpreted as meaning that with an increase of HIV prevalence by one unit, while the rest of the independent variables remain unchanged, the value of the dependent variable (HDI) will increase by 0.0072 . In other words, the $\beta_{1}$ parameter expresses that if HIV prevalence is increased by $1 \%$, while the Corruption Perceptions Index and the Index of Economic Freedom remain unchanged, the Human Development Index will increase by $0.7 \%$. The equation supplemented with numerical parameters has the form:

$$
\begin{gathered}
\text { HDI_2017 }=0,231+0,00723 * H I V \_2015-0,00136 * C P I \_2015+ \\
0,00533 * I E F \_2015
\end{gathered}
$$

Our first step, when testing the significance of parameters in gretl, was to test the following pair of hypotheses:

$$
\boldsymbol{H}_{0}: \beta_{0}=0 \text { and } \boldsymbol{H}_{1}: \beta_{0} \neq 0 \text {. }
$$

The value of the t-ratio parameter in line with the constant is 2.391 .

The T-test critical value at the 0.025 significance level for 35 degrees of freedom equals 2.03011 .

The T-test absolute value (2.391) is higher than its calculated critical value (2.030), and therefore we can reject the zero hypothesis and state that $\beta_{0}$ parameter is statistically significant at the significance level of $5 \%$.

We verified the significance of the remaining parameters in a similar manner. When we focus on the $\beta_{1}$ parameter, the T-test of the HIV prevalence parameter in absolute value equals 3.485. Comparing the absolute value with the critical value of 2.03011, we conclude that the $\beta_{1}$ parameter is also statistically significant at the significance level of $5 \%$. The same holds for the $\beta_{3}$ parameter (Index of Economic Freedom). The T-test of the $\beta_{2}$ parameter (Corruption Perception Index) in absolute value equals 1.052, and thus when compared with its critical value it can be regarded as statistically insignificant.

The significance of the regression model, taken as a whole, was verified via an F-test, and its value equals 7.321334 while its critical value at the significance level of $5 \%$ equals 2.87419. The absolute value exceeds its calculated critical value, and therefore we can state that the regression model is at the significance level of $5 \%$ statistically significant. When the White test (the test of heteroscedasticity of random components) was carried out, we obtained a WH value of 3.12017 and a critical value of 16.919. The WH value is lower than the critical value, we therefore accept the null hypothesis at the 5\% significance level, and state that heteroscedasticity is not present in the model.

The coefficient of determination $R^{2}$ serves for assessing the quality of the model—we used it to determine what proportion of variability of the Human Development Index (the dependent variable) is explained by our regression model. We interpret the resulting value of the coefficient of determination 0.3856 as follows: the regression model with independent variables represented by HIV prevalence, the Corruption Perceptions Index and the Index of Economic Freedom allows us to explain $38.56 \%$ of the variability of the Human Development Index. The remaining $61.44 \%$ of the variability of the Human Development Index is caused by factors that were not included in the regression model as well as by further random effects. The extremes that cause the value of the coefficient of determination to be lowered are shown in Figure 1. 
Figure 1: Countries assessed as extremes by GRETL program

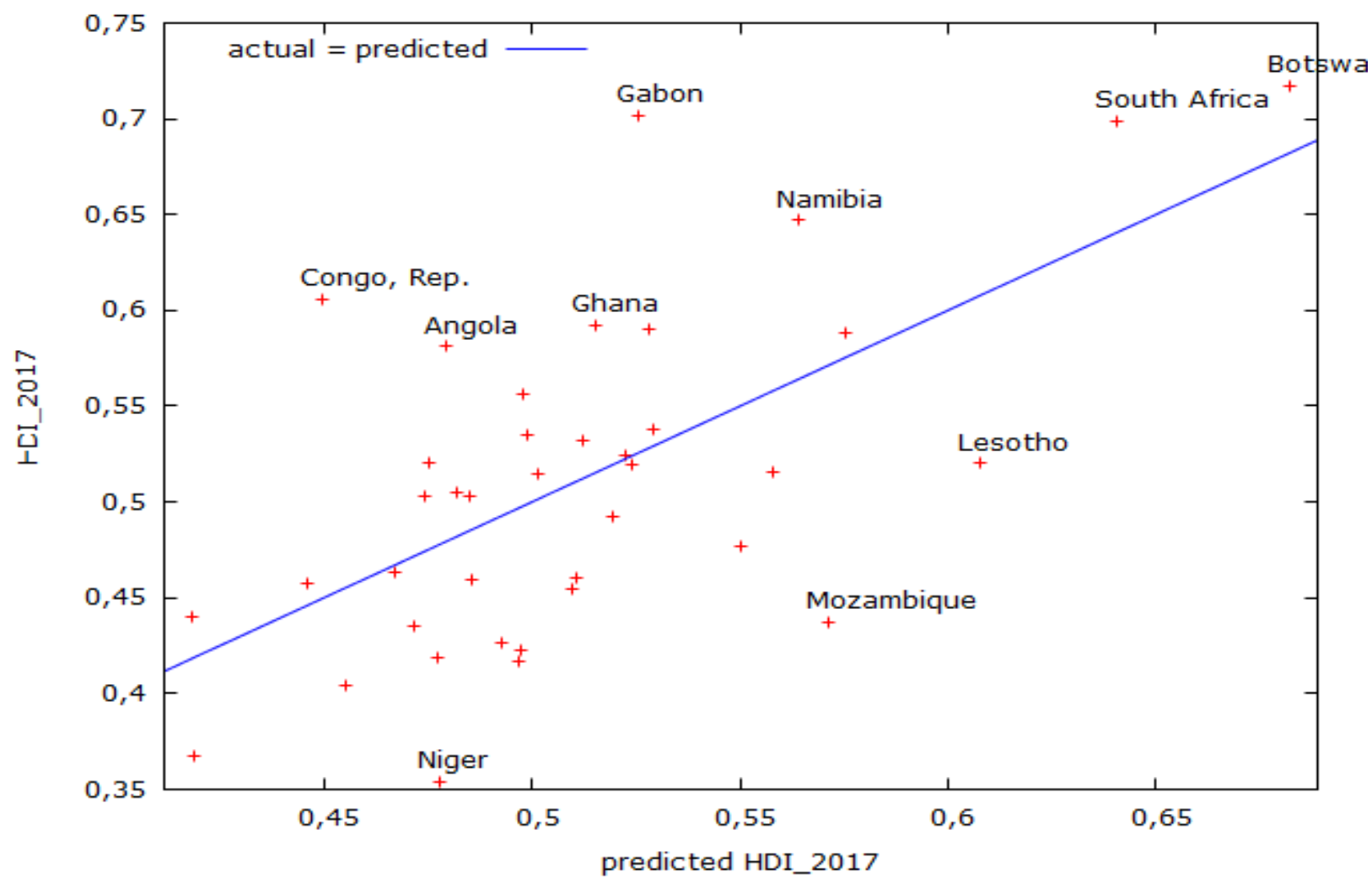

Source: Authors' own elaboration in gretl based on the following data: UNDP (2017), World Bank, (2015), Transparency International, (2016) and the Heritage Foundation, (2015).

The countries assessed as extremes were primarily the following: Nigeria, Lesotho, Botswana, RSA, Namibia, Gabon, Ghana, Angola, and Congo, Rep. - nations that are, according to their GDP per capita, relatively wealthy, and at the same time, paradoxically, have a relatively high HIV prevalence. The only exception from the extremes shown is Mozambique which has the sixth highest HIV prevalence out of the surveyed countries, and simultaneously is the fifth poorest country in the area.

The analysis confirmed a proportional relationship between the Human Development Index and HIV prevalence and showed that high HIV prevalence does not automatically lead to extreme poverty. HIV is therefore not a key factor in the countries' economic development, but rather contributes to the impact of several factors affecting the development of SubSaharan Africa.

\section{Discussion}

HIV infection is one of the world's most serious public health challenges as well as one of the most serious global social and economic problems. For Sub-Saharan Africa, mainly in its southern part, with two thirds of world's infected population, the consequences of high HIV prevalence have serious impact on various levels of everyday life: poverty, overall health conditions, working condition, social structures, and possibilities of development. Nevertheless, our hypothesis that the poorest states of Sub-Saharan Africa will be the most significantly affected by HIV/AIDS epidemic, was not confirmed.

Our regression model in gretl confirmed the paradox evident by comparing the values of GDP per capita and HIV prevalence. HIV prevalence rates are higher in relatively richer countries of Sub-Saharan Africa, those with higher GDP per capita and higher values of the 
Human Development Index. Our assumption, that a "richer" country would have more sources to fight the epidemic and thus lower HIV prevalence rates does not apply. Our results are also in line with Dauda's (2017) research which came to the conclusion, that an increase in GDP per capita does not increase human capital development, and countries spent little to improve human development - the relatively wealthier Southern African countries do not report better HIV prevalence results. The problems of the region which limit the prospect of reduction in HIV prevalence include HIV/AIDS stigmatization; discrimination of HIV positive people; inefficiency of health campaigns, cultural habits, and tenets. The model 'proposed by Lou et al. (2014) shows that HDI had a negative effect on HIV, our model confirmed that HIV itself does not lead to a decrease in HDI and that poverty is a more complex problem influenced by many variables.

\section{Conclusion}

The phenomenon of the poverty is such a complex issue that its simplification and tying exclusively to the HIV infection is not possible. The public health issue is only one of the many factors hindering countries' economic development. HIV certainly has a negative impact on countries' prosperity and population health, and is a source of negative social and emotional effects, however, it is not the crucial determinant negatively affecting the overall development.

The UNAIDS intention to end the infection by 2030, raise AIDS-free youth, and eliminate discrimination of HIV positives, despite the medical progress and aid development aid, seems to be unattainable.

\section{References}

Abdulsalam, S. (2010). Macroeconomic effects on HIV/AIDS prevalence and policy in Nigeria: A simulation analysis. Forum for Health Economics and Policy, 12(2).

Assiedu, E., Jin, Y., \& Kanyama, I. K. (2015). The impact of HIV/AIDS on foreign direct investment: Evidence on Sub-Saharan Africa. Journal of African Trade, 2(1-2), 1-17.

Avert (2020). HIV and AIDS in the Middle East and North Africa (MENA). https://www.avert.org/professionals/hiv-around-world/middle-east-north-africa-mena.

Bhargava, A., \& Docquier, F. (2008). HIV pandemic, medical brain drain, and economic development in SubSaharan Africa. The World Bank Economic Review, 22(2), 345-366.

Bonnel, R. (2000). HIV/AIDS and economic growth: A global perspective. World Bank. http://citeseerx.ist.psu.edu/viewdoc/download?doi=10.1.1.201.8357\&rep=rep1\&type=pdf

Dauda, R. S. (2018). Impact of HIV/AIDS epidemic on human capital development in West Africa. Health Planning and Management, 33(2), 460-478.

Dixon, S., McDonald, S., \& Roberts, J. (2002). The impact of HIV and AIDS on Africa's economic development. British Medical Journal, 324, 232-234.

Essig, A., Kang, S., Sellers, R. (2015). The relationship between HIV infection rates and GDP per capita in African countries. Georgia Institute of Technology: Atlanta, GA, USA. https://smartech.gatech.edu/bitstream/handle/1853/53303/hivandgdpecon3161.pdf.

Gezahegn, M., \& Upadhyay, M. (2014). The effect of HIV/AIDS on economic growth on Southern African countries. Asian Economic and Financial Review, 4(9).

Haruna, M. A. (2017). The socio-economic effects of HIV/AIDS in Sub-Saharan Africa: The Nigerian case. Journal of Poverty, Investment and Development, (37).

HIV.gov. (2017). Global statistics. Global health. <https://www.hiv.gov/hiv-basics/overview/data-andtrends/global-statistics>.

HIV.gov. (2020). Global statistics. The global HIV/AIDS epidemic. <https://www.hiv.gov/hivbasics/overview/data-and-trends/global-statistics>.

Johnston, D., Deane, K., \& Rizzo M. (2015). The political economy of HIV. Review of African Political Economy, 42(145), 335-341. 
Justman, J. et al. (2011). Swaziland HIV incidence measurement survey (SHIMS): A prospective national cohort study. The Lancet, 4(2), 83-92.

KFF (2019) The global HIV/AIDS epidemics. <https://www.kff.org/global-health-policy/fact-sheet/the-globalhivaids-epidemic/>.

Leon, J., Baker, D. P., \& Salinas, D. (2017). Is education a risk factor or social vaccine against HIV/AIDS in Sub-Saharan Africa? The effect of schooling across public health periods. Journal of Population Research, 34(4), 347-372.

Lou, Ch. et al. (2014). National HIV/AIDS mortality, prevalence, and incidence rates are associated with the Human Development Index. American Journal of Infection Control, 42(10), 1044-1048.

Lovasz, E., \& Schipp, B. (2009). The impact of HIV/AIDS on economic growth in Sub-Saharan Africa. South African Journal of Economics, 77(2), 245-256.

Lukacik, M., Lukacikova, A., \& Szomolanyi, K. (2011). Ekonometrické Modelovanie v Programoch EVIEWS a GRETL. Bratislava: Vydavatel'stvo EKONÓM.

Maijama'a, D., \& Mohammed, K. B. (2013). Impact of HIV/AIDS on economic growth and development in Nigeria. SSRN Electronic Journal. <https://ssrn.com/abstract=2695373>.

Nketiah-Amponsah, E., Abubakari, M., \& Baffour, P. T. (2019). Effect of HIV/AIDS on economic growth in Sub-Saharan Africa: Recent evidence. International Advances in Economic Research, 25, 469-480.

Odugbesan, J. A., \& Rjoub, H. (2020). Evaluating HIV/AIDS prevalence and sustainable development in subSaharan Africa: The role of health expenditure. African Health Science, 20(2), 568-578.

Oraby, D. (2018). Women living with HIV in the Middle East and north Africa. The Lancet Public Health Correspondence, 3(2).

The Heritage Foundation. (2015). Index of economic freedom: Promoting economic opportunity and prosperity. <https://www.heritage.org/index/pdf/2015/book/index_2015.pdf>

Transparency International (2016). Corruption Perceptions Index 2015. $<$ https://www.transparency.org/cpi2015>

UNAIDS. (2020). Global factsheets. <http://aidsinfo.unaids.org/>

UNDP. (2017). Human development data (1990-2017). <http://hdr.undp.org/en/data>

Whiteside, A. (2002). Poverty and HIV/AIDS in Africa. Third World Quarterly, 23(2), 313-332.

World Bank (2015). Prevalence of HIV, total (\% of population ages 15-49). <https://data.worldbank.org/indicator/SH.DYN.AIDS.ZS>

World Bank (2019). Data. Sub-Saharan Africa. https://data.worldbank.org/region/sub-saharanafrica?view $=$ chart. 